\title{
Conduct Disorder
}

National Cancer Institute

\section{Source}

National Cancer Institute. Conduct Disorder. NCI Thesaurus. Code C89329.

A disorder diagnosed in childhood or adolescence age group characterized by agg ressive behavior, deceitfulness, destruction of property or violation of rules that is persistent and repetitive, and within a one year period. 